\title{
Effect of the silencing of the Ehcp112 gene on the in vitro virulence of Entamoeba histolytica
}

\author{
Ramón Ocádiz-Ruiz' ', Wendy Fonseca', Máximo B Martínez², Ramón Ocádiz-Quintanar', Esther Orozco \\ and Mario A Rodríguez ${ }^{1 *}$
}

\begin{abstract}
Background: Entamoeba histolytica is an intestinal protozoan parasite that causes amoebiasis in humans, affecting up to 50 million people worldwide each year and causing 40,000 to 100,000 deaths annually. EhCP112 is a cysteine proteinase of E. histolytica able to disrupt cell monolayers and digest extracellular matrix proteins, it is secreted by trophozoites and it can be active in a wide range of temperature and $\mathrm{pH}$. These characteristics have encouraged the use of EhCP112 in the design and production of possible vaccines against amoebiasis, obtaining promising results. Nevertheless, we have no conclusive information about the role of EhCP112 in the E. histolytica pathogenesis.
\end{abstract}

Methods: A set of three specific siRNA sequences were used to silence the Ehcp 112 gene via the soaking system. Silencing was evaluated by Western blot using an antibody against the EhCP112 recombinant protein. Finally, we analyzed the protease activity, the phagocytosis rate and the ability to destroy MDCK cells of the EhCP112-silenced trophozoites.

Results: The highest silencing effect on EhCP112 was detected at $16 \mathrm{~h}$ of treatment; time enough to perform the in vitro virulence assays, which showed that EhCP112 silencing produces a significant reduction in cytolysis and phagocytosis of target cells, indicating the participation of this proteinase in these events.

Conclusions: EhCP112 is involved in the in vitro virulence of E. histolytica.

Keywords: Entamoeba histolytica, Cysteine proteinases, EhCP112, siRNA-mediated silencing

\section{Background}

Entamoeba histolytica is the intestinal protozoan parasite that causes amoebic colitis and amoebic liver abscesses in humans [1], affecting up to 50 million people worldwide each year and causing 40,000 to 100,000 deaths annually [2]. The cytopathogenic mechanism of this parasite consists of three main steps: adherence, cytolysis, and phagocytosis [3] and several molecules, including cysteine proteinases (CPs), participate in these events [4].

CPs have been identified as crucial virulence factors of protozoa parasites because they are associated to cytoadherence, haemolysis, cytotoxicity, degradation of extracellular matrix components, evasion of the immune response and nutrient acquisition [5-10]. The

\footnotetext{
* Correspondence: marodri@cinvestav.mx

'Departamento de Infectómica y Patogénesis Molecular, CINVESTAV-IPN, A.P. 14-740, México, D.F., México

Full list of author information is available at the end of the article
}

characterization of CP genes and their products have confirmed their relevance in invasion and colonization of host tissues [11-20]. As in other parasites, CPs play an important role in the pathogenicity of E. histolytica [21]. The genome of this parasite contains around fifty genes encoding CPs, although only few of them are expressed at significant levels in trophozoites grown in culture media $[22,23]$. Those CPs not expressed in vitro are thought to play a role in infection of the human host, invasion and destruction of host tissue and completion of the parasite life cycle [21].

EhCPADH is a protein complex of E. histolytica formed by the EhCP112 cysteine proteinase and the EhADH112 adhesin [24]. This complex is located in cytoplasmic vesicles and plasma membrane of trophozoites and is diminished in adherence- and virulence-deficient mutants [25]. EhCP112 contains a putative transmembranal domain and a RGD sequence for interaction with integrins [24]. The

\section{Biomed Central}


recombinant EhCP112 protein (rEhCP112) disrupts cell monolayers, digests extracellular matrix proteins and is active in a wide range of temperature and $\mathrm{pH}[26,27]$. The results obtained with the recombinant protein suggest that EhCP112 could be involved in the pathogenic mechanism of this parasite; however, the relevance of EhCP112 in the virulence of $E$. histolytica has not been proved directly.

Here, we found that RNAi-mediated downregulation of EhCP112 in E. histolytica trophozoites leads to a reduction of the in vitro virulence of the parasite.

\section{Methods}

\section{Entamoeba histolytica cultures}

Trophozoites of clone A [28], strain HM1: IMSS, were axenically cultured in TYI-S-33 medium and harvested during the logarithmic growth phase as previously described [29].

\section{Expression and purification of the recombinant EhCP112 protein}

An Ehcp112 gene fragment (1278 bp), which encodes a polypeptide containing the pro-peptide and the mature enzyme, cloned in the expression vector pTrcHIs C [26] was used to transform bacteria E. coli, strain BL21 (pLys E). These bacteria were incubated with $1 \mathrm{mM}$ of Isopropyl $\beta$-D-1-thiogalactopyranoside (IPTG) for $3 \mathrm{~h}$ at $37^{\circ} \mathrm{C}$ [30] to induce the production of the recombinant protein. Then, the EhCP112 recombinant protein (rEhCP112), containing a poly-histidine tag, was purified through $\mathrm{Ni}^{2+}$-affinity columns (Qiagen, USA) following the manufacturer's protocol.

\section{Antibody generation}

To obtain antibodies against $\mathrm{rEhCP} 112,100 \mu \mathrm{g}$ of the recombinant protein was subcutaneously inoculated four times at intervals of 15 days on New Zealand rabbits. The first immunization was performed in the presence of complete Freund's adjuvant (Sigma-Aldrich), and additional immunizations were carried out in the presence of incomplete Freund's adjuvant (Sigma-Aldrich). The experimental protocol was approved by the institutional committee for animal care and provided all technical specifications for the production, care and use of laboratory animals (NOM-062-ZOO-1999).

\section{siRNA design}

The complete Ehcp112 mRNA sequence (GenBank: AF127375.2) was analyzed by the online program Target finder [31] to obtain potential small interference RNA (siRNA) sequences. Then, the multiple hypothetic sequences acquired were evaluated by nucleotide BLAST [32], and by the multiple sequence alignment ClustalW [33], comparing all the sequences reported in the Entamoeba genome database Pathema [34], including all E. histolytica CPs. A set of three specific siRNA oligonucleotide sequences for Ehcp112 were chosen (Table 1) and they were sent to their synthesis (Ambion). As a negative control, an additional set of scrambled sense and antisense primers with a non-related sequence (NRS) were synthesized.

\section{siRNA preparation}

All primers were diluted to $1 \mu \mathrm{g} / \mu \mathrm{l}$ in TE $(10 \mathrm{mM}$ Tris$\mathrm{HCl}, 1 \mathrm{mM}$ EDTA) and then, respective sense and antisense oligonucleotides were hybridized using the $1 \mathrm{X}$ DNA Annealing Solution (Ambion) incubating at $90^{\circ} \mathrm{C}$ for $3 \mathrm{~min}$ and then at $37^{\circ} \mathrm{C}$ for $1 \mathrm{~h}$.

\section{Soaking of $E$. histolytica trophozoites with siRNA}

Trophozoites $\left(1 \times 10^{6}\right)$ freshly collected from 90\% confluent cultures were inoculated in $25 \mathrm{ml}$ culture plastic flasks (Corning) containing TYI-S-33 medium and incubated at $37^{\circ} \mathrm{C}$ during $24 \mathrm{~h}$. Then the annealed siRNAs at 25,50 and $100 \mu \mathrm{g} / \mathrm{ml}$ were added to the cultures and incubated at $37^{\circ} \mathrm{C}$ for 16,24 , and $36 \mathrm{~h}$. To verify the siRNA entry to trophozoites by this soaking method, 75 pmol of a fluorescein-labeled negative control siRNA (Ambion) were added to $1 \times 10^{6}$ trophozoites during 2, 5 and $16 \mathrm{~h}$ and internalization of the labeled-siRNA was analyzed by confocal microscopy. To determine the effect of the EhCP112 silencing on growth, the number of trophozoites and its viability was analyzed by trypan blue staining each $12 \mathrm{~h}$ after soaking with siRNA.

\section{Western blot assays}

Total extracts from $E$. histolytica were separated by $10 \%$ SDS-PAGE and transferred to nitrocellulose membranes. Then, membranes were incubated with antibodies against rEhCP112 (1:10,000), followed by incubation with a mouse anti-rabbit IgG secondary antibody conjugated to horseradish peroxidase (Invitrogen) (1:10,000). Finally, the antibody detection was developed by incubation with 3,3'-diaminobenzidine tetrahydrochloride (Sigma-Aldrich) and $\mathrm{H}_{2} \mathrm{O}_{2}$. As internal control, the same membranes were revealed with anti-actin antibodies

\section{Table 1 siRNA sequences}

\begin{tabular}{ll}
\hline siRNA 1 & Target sequence: 5'-AATCAAAAGACTCAAAGCATT-3' \\
& Sense strand: 5'-UCAAAAGACUCAAAGCAUUUU-3' \\
siRNA 2 & Antisense strand: 5'-AAUGCUUUGAGUCUUUUGAUU-3' \\
& Target sequence: 5'-AATTGCTGTAAAATCCTITC-3' \\
& Sense strand: 5'-UUGCUGUAAAAUCCUUUUCUU-3' \\
siRNA 3 & Antisense strand: 5'-GAAAAGGAUUUUACAGCAAUU-3' \\
& Target sequence: 5'-AAATATTTGTAGTTCATGTGT-3' \\
& Sense strand: 5'-AUAUUUGUAGUUCAUGUGUUU-3' \\
& Antisense strand: 5'-ACACAUGAACUACAAAUAUUU-3'
\end{tabular}


(1:20,000). The bands detected by the anti-EhCP112 antibodies were analyzed by densitometry and data were normalized with those obtained from bands recognized by the anti-actin antibodies.

\section{Protease activity}

To analyze the protease activity, trophozoites were washed twice with phosphate-buffered saline (PBS) and suspended at concentration of $10^{7} / \mathrm{ml}$ in PBS. The cellular pellets were lysed by five freeze-thaw cycles in liquid $\mathrm{N}_{2}$ and $10 \mu \mathrm{l}$ of a 1:1000 dilution were mixed with $10 \mu \mathrm{l}$ of $2 \times$ sample buffer without 2-mercaptoethanol and electrophoresed in 10\% SDS-PAGE copolymerized with $0.1 \%$ gelatin. After electrophoresis, gels were incubated in $2.5 \%$ Triton $\times-100$ for $1 \mathrm{~h}$ at room temperature. CPs were activated by incubation in buffer activation (Tris$\mathrm{HCl} 0.1 \mathrm{M}$ pH $6.8, \mathrm{CaCl}_{2} 10 \mathrm{mM}$ and $0.02 \%$ 2mercaptoethanol) for $12-16 \mathrm{~h}$ at $37^{\circ} \mathrm{C}$. Gels were stained with $0.25 \%$ Coomassie blue R-250 and clear bands were indicative of proteolytic activity.

\section{Cytotoxic and cytophatic assays}

MDCK (Madin-Darby canine kidney) monolayers ( $1 \times$ $10^{5}$ cells) grown in 24-well plates (Costar) were incubated with $1 \times 10^{5}$ trophozoites (cytopathic assays) or with total extracts from $1 \times 10^{6}$ trophozoites (cytotoxic assays) in the presence of $0.02 \%$ of 2 -mercaptoethanol during $2 \mathrm{~h}$ at $37^{\circ} \mathrm{C}$. After this time, trophozoites or their extracts were eliminated and the remaining monolayers were washed three times with PBS, fixed with $2.5 \%$ glutaraldehyde, and cellular destruction was evaluated as previously described [35]. Briefly, cells were stained with $1 \%$ methylene blue, washed extensively and the dye captured by the rest of the monolayers was extracted with $0.1 \mathrm{~N} \mathrm{HCl}$ and read in a spectrophotometer (Bechman coulter DU800) at $660 \mathrm{~nm}$. Results were reported as the means \pm standard deviation of three independent experiments by duplicate.

\section{Erythrophagocytosis}

Erythrophagocytosis was measured using human red blood cells (hRBCs) as previously described [36], with some modifications. Fresh hRBCs $(\mathrm{O} \mathrm{Rh}+)$ from healthy donors were washed three times and resuspended in serum-free amoeba culture medium. Then, trophozoites were incubated with hRBCs at a ratio of 1:100 [28] at $37^{\circ} \mathrm{C}$ with slight agitation for 5 and $10 \mathrm{~min}$, the standard gap of time in the study of phagocytosis in E. histolytica [28]. Then, the non-ingested erythrocytes were lysed by incubation with distilled water for $10 \mathrm{~min}$ at room temperature and trophozoites were washed three times with PBS. Finally, samples were centrifuged at $360 \times \mathrm{g}$ during $5 \mathrm{~min}$ and pellets of amoebae with internalized hRBCs were resuspended in $1 \mathrm{ml}$ of concentrated formic acid (J.T. Baker). Finally, the absorbance at $405 \mathrm{~nm}$ of the samples was measured against a blank of formic acid using a spectrophotometer (Beckman coulter DU800). Data were normalized using the formula $A_{405}$ of sample/ $A_{405}$ of control trophozoites (NRS-treated) at $10 \mathrm{~min}$ of phagocytosis. Results were reported as the means \pm standard deviation of the percentage of normalized values of three independent experiments by duplicate.

\section{Results and discussion}

\section{Generation of antibodies against EhCP112}

EhCPADH is a protein complex formed by a CP (EhCP112) and an adhesin (EhADH112) [24]. This complex is located in cytoplasmic vesicles and plasma membrane of trophozoites [24,25]. EhCP112 and EhADH112 have been independently characterized [24,26,27,37]. In particular, the study and characterization of EhCP112 suggest that this protein could play an important role in the virulence of $E$. histolytica $[24,26,27,38]$, but there is not a conclusive study about the role of EhCP112 in the E. histolytica pathogenesis.

The RNAi technology has proved to be a strong tool in molecular biology to study the functional analysis of cellular genes $[39,40]$ and also for the development of novel therapeutic drugs to treat various incurable diseases $[41,42]$. Indeed, this technology has been useful in the study of E. histolytica [43-47]. Consequently, to confirm that EhCP112 is involved in the E. histolytica pathogenesis, we analyzed the in vitro virulence of EhCP112-silenced trophozoites.

To analyze the EhCP112 silencing, first we obtained specific antibodies against the recombinant EhCP112 (rEhCP112) [26]. Thus, the pTrcHIs-EhCP112 construction, encoding the pro-peptide and the mature enzyme [26], was expressed in bacteria E. coli, strain BL21 (pLys E). In SDS-PAGE of extracts of induced bacteria we observed a slight enrichment of a $52-\mathrm{kDa}$ protein (Figure 1A), the expected molecular weight of rEhCP112 containing the poly-histidine tag encoded by the vector. Then, through $\mathrm{Ni}^{2+}$-NTA affinity columns we purified two polypeptides of 52 and $43 \mathrm{kDa}$ (Figure 1A). These polypeptides correlate with the expected molecular weight of the pro-enzyme $(52 \mathrm{kDa})$ and the mature enzyme $(43 \mathrm{kDa})$ variants of EhCP112 containing the poly-histidine tag, suggesting that rEhCP112 is an active enzyme [26].

In order to generate antibodies against EhCP112, New Zealand rabbits were subcutaneously inoculated with $100 \mu \mathrm{g}$ of the purified rEhCP112. Then, the antibodies obtained were tested by Western blot. In these assays, two bands were recognized in both the recombinant protein and trophozoite extracts (Figure 1B, C). These bands correspond to the expected molecular weight of the pro-enzyme and the mature enzyme. No bands were detected by the preimmune serum in trophozoite 


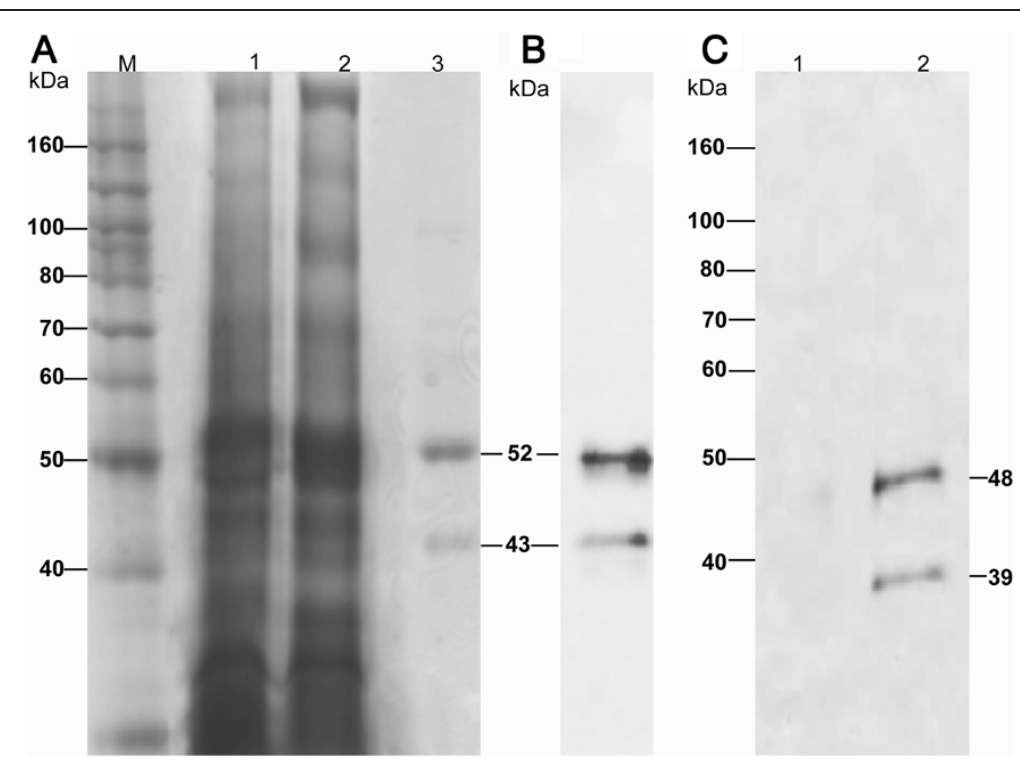

Figure 1 Expression and purification of rEhCP112 and antibodies generation. (A) Expression and purification of rEhCP112. An Ehcp 112 gene fragment (encoding the pro-peptide and the mature enzyme) cloned in the pTrcHIs C expression vector was expressed in E. coli. Then, the rEhCP112 was purified through $\mathrm{Ni}^{2+}$-affinity columns and analyzed by SDS-PAGE. Lane M, molecular weight markers; lane 1, uninduced bacteria extracts; lane 2, bacteria extracts induced by IPTG; lane 3, purified proteins corresponding to the pro-peptide and mature enzyme (52 and $43 \mathrm{kDa}$ ). (B) Antibodies generation. The rEhCP112 was inoculated in rabbits. Then, serum was tested by Western blot assays using the rEhCP112 in a SDS-PAGE. (C) Western blot on E. histolytica extracts. To analyze the specificity of the antibody against rEhCP112 we performed Western blot assays on total extracts of E. histolytica trophozoites; Lane 1, control using the preimmune serum; lane 2, antibody against rEhCP112.

extracts (Figure 1C), suggesting that antibodies are specific against EhCP112.

\section{siRNA design}

Once we had specific antibodies against EhCP112, we designed the siRNA sequences using the complete mRNA sequence of this CP (GenBank: AF127375.2) as target. The online program Target finder [31] predicted 70 hypothetic target sequences. To determine the specificity of these potential target sites, we used the BLAST tool of the Entamoeba genome database Pathema [34] and the NCBI BLAST tool [32]. We eliminated from consideration any target sequence with more than 10 contiguous base pairs of homology to other coding sequences in E. histolytica.

A set of three specific EhCP112 siRNA oligonucleotide sequences were chosen (Table 1). These sequences are located towards the $5^{\prime}$-end (siRNA 1), in the middle of the mRNA sequence (siRNA 2), and towards the 3 'end (siRNA 3), they did not show significant homology to other mRNAs encoding E. histolytica genes, included other CPs. As a negative control, an additional set of non-related sense and antisense primers were used.

\section{Internalization of siRNA}

Before performing the EhCP112-silencing, the entry of siRNA into the trophozoites by the soaking method was verified by confocal microscopy using a fluorescentlabeled siRNA. In these experiments we observed that since 5 min of incubation, the siRNA was bound to the plasma membrane of the trophozoites, and a weak punctuated label was detected inside the trophozoites (Figure 2A). At $2 \mathrm{~h}$ of incubation the labeled-siRNA was detected dispersed in the interior of the trophozoites (Figure 2B); and at longer times ( 5 and $16 \mathrm{~h}$ ), siRNA was observed as fluorescent spots inside the trophozoites (Figure 2C, D), but these spots were smaller after $16 \mathrm{~h}$ of incubation (Figure 2D). These results showed that siRNAs are efficiently internalized into the trophozoites by the soaking method.

\section{EhCP112 silencing}

In order to evaluate the silencing of EhCP112, we analyzed its expression by Western blot in trophozoites incubated with the three siRNAs sequences at three different concentrations $(25,50$ and $100 \mu \mathrm{g} / \mathrm{ml})$ for 16 , 24 and 36 h. Each siRNA was tested separately and mixed. In these assays we observed a decreased expression of EhCP112 in trophozoites treated for 16 and $24 \mathrm{~h}$ with $50 \mu \mathrm{g} / \mathrm{ml}$ of the siRNA 1 , corresponding to the $5^{\prime}$ end of the gen, whereas the EhCP112 expression was not affected by incubation with the siRNA control, containing a non-related sequence (NRS) (Figure 3A). As internal control we performed Western blot assays 

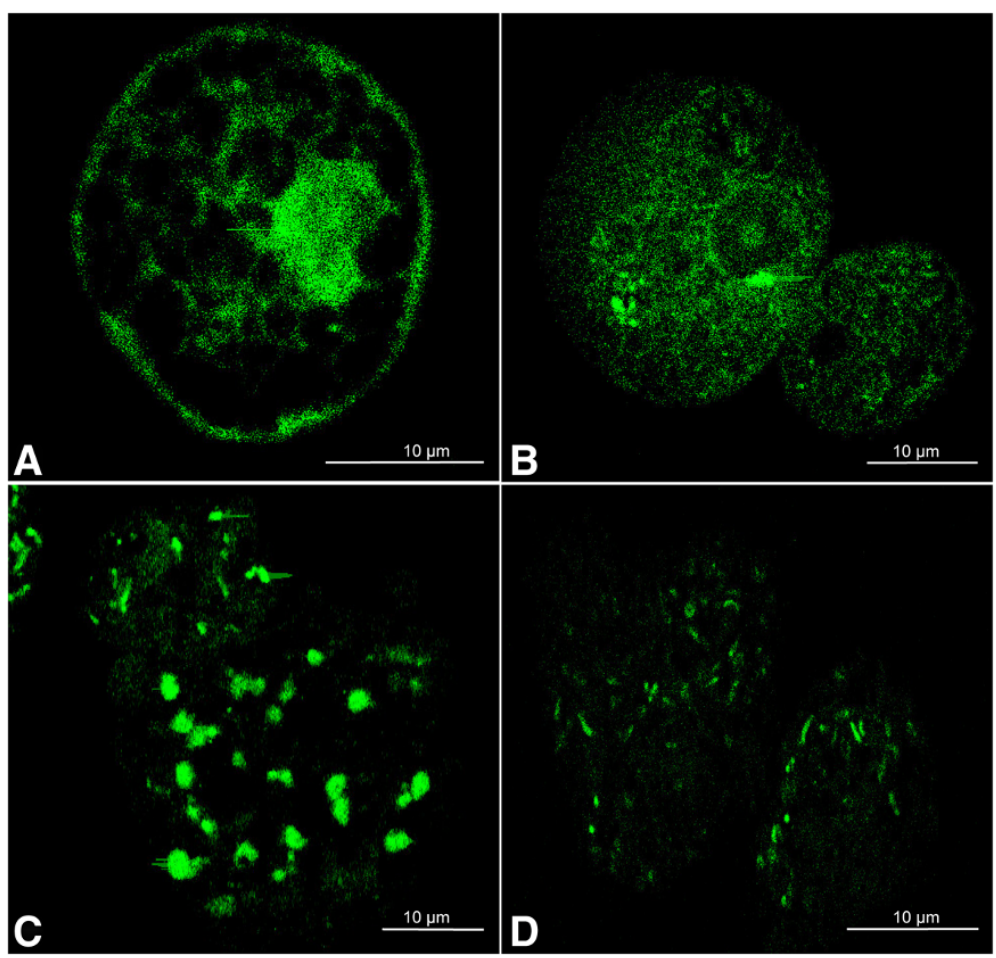

Figure 2 Analysis of internalization of a fluorescein-labeled siRNA. Trophozoites were incubated at several times with a fluorescein-labeled siRNA via soaking method. The entry to trophozoites was verified by confocal microscopy. (A) 5 minutes incubation; (B) 2 hours incubation; (C) 5 hours incubation; (D) 16 hours incubation.

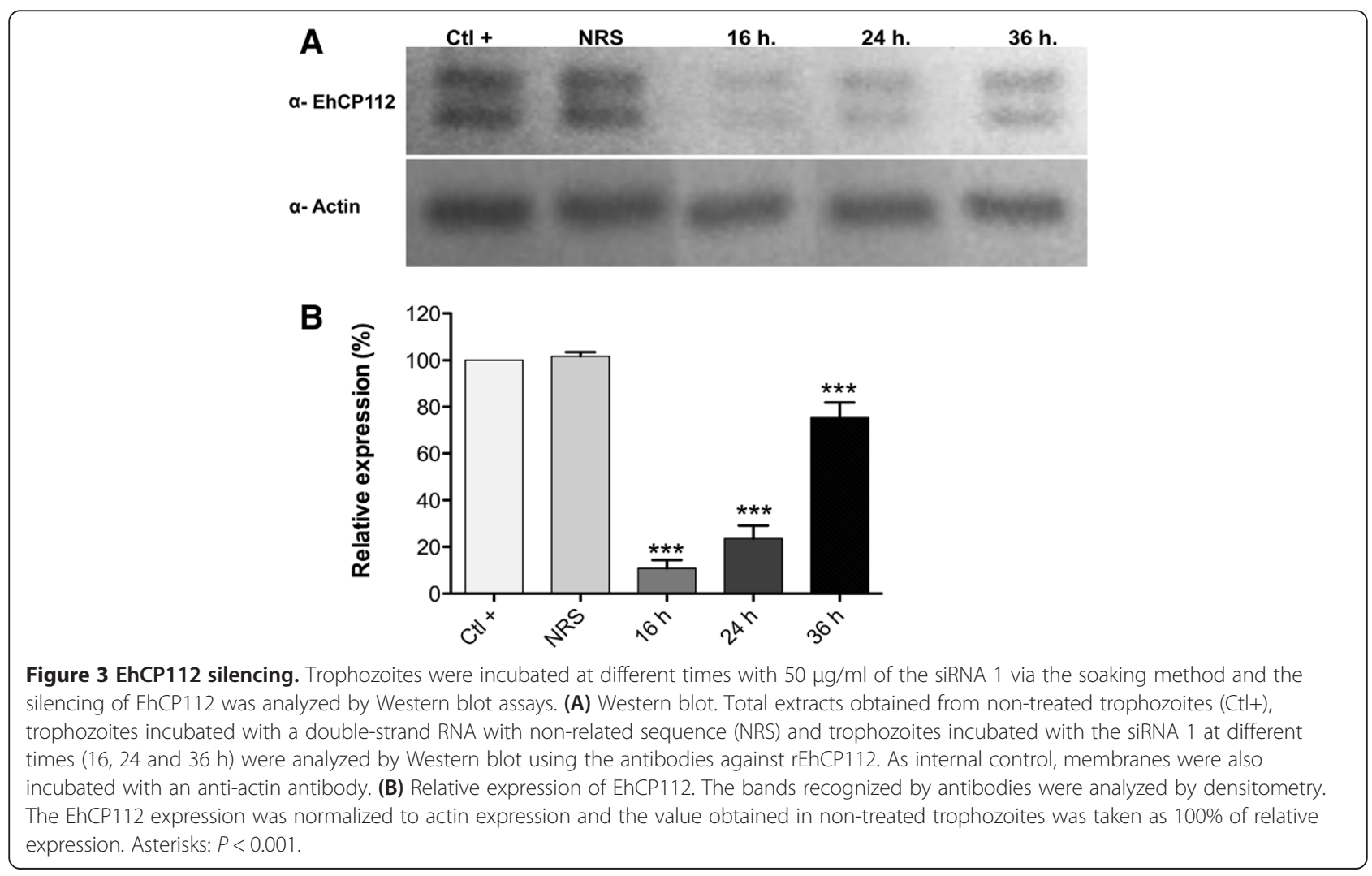


using an anti-actin antibody, which detected a $45-\mathrm{kDa}$ band with almost the same intensity in all samples (Figure 3A). Densitometry of the bands detected, showed that the EhCP112 expression decreased in 89 and $76 \%$, after 16 and $24 \mathrm{~h}$ of incubation, respectively (Figure 3B). However, after $36 \mathrm{~h}$ of incubation, the expression of EhCP112 decreased only 25\% (Figure 3B), indicating that the silencing effect was reversible and dose dependent. Some authors have been reported that in eukaryotic cells, the siRNA in the RNAi process is degraded together with the mRNA, thus the process is not continue [41,42]. On the other hand, the EhCP112 silencing had no effect on the proliferation of the trophozoites (data not shown), suggesting that this $\mathrm{CP}$ is not needed for growth in culture medium.

The incubation of trophozoites with $100 \mu \mathrm{g} / \mathrm{ml}$ of siRNA 1 not increased the EhCP112 silencing (data not shown). In addition, siRNA 2 and siRNA 3 did not show a significant effect in the EhCP112 expression. Consequently, the incubation with the siRNA mixture did not increase the EhCP112 silencing caused by siRNA 1 (data not shown). Then, consecutive experiments were performed
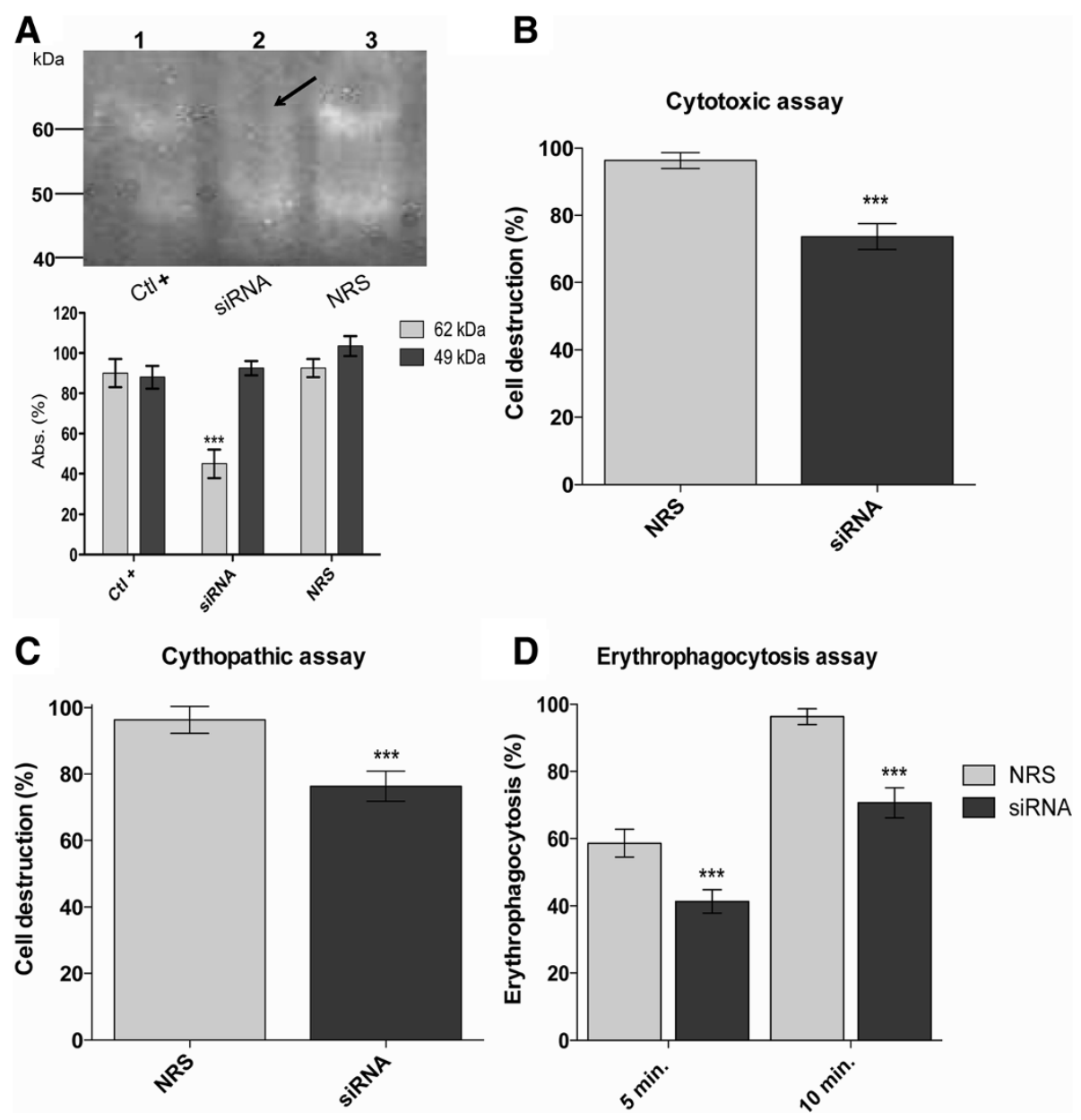

Figure 4 In vitro virulence of Ehcp112-silenced trophozoites. (A) Protease activity. The protease activity of the trophozoites treated by $16 \mathrm{~h}$ with the siRNA 1 (EhCP112-silenced trophozoites) was analyzed in polyacrylamide-0.1\% gelatin substrate gels. Lane 1, extracts from untreated trophozoites $(\mathrm{Ct} \mid+)$; lane 2, extracts from EhCP112-silenced trophozoites (SiRNA); lane 3, extracts from trophozoites treated with a non-related sequence (NRS). Arrow indicates the 62-kDa band with minor proteolytic activity in EhCP112-silenced trophozoites. Below is shown the densitometry of the proteinase activity of the 62- and 49-kDa bands. (B) Cytotoxic activity. Total extracts from EhCP112-silenced trophozoites (SiRNA) and NRS-treated trophozoites (NRS) were incubated with MDCK monolayers during $2 \mathrm{~h}$. Then, the monolayer destruction was evaluated. (C) Cytopathic assays. EhCP112-silenced trophozoites (SiRNA) and NRS-treated trophozoites (NRS) were incubated with MDCK monolayers during $2 \mathrm{~h}$. Then, the monolayer destruction was evaluated. (D) Erythrophagocytosis assays. EhCP112-silenced trophozoites (SiRNA) and NRS-treated trophozoites (NRS) were incubated with human red blood cells during 5 and $10 \mathrm{~min}$. Then, the ingestion of the target cells was evaluated and value obtained with the NRS-treated trophozoites at 10 min of phagocytosis was arbitrary taken as 100\% efficiency. Data were analyzed in three independent assays by duplicate and they are expressed as the means \pm standard deviation. Differences were evaluated by t-student test. Asterisks: $P<0.001$. 
with trophozoites after $16 \mathrm{~h}$ of treatment with $50 \mu \mathrm{g} / \mathrm{ml}$ of siRNA 1, because in these conditions we observed the most efficient effect on the EhCP112 silencing.

\section{Effect of the EhCP112 silencing on the E. histolytica in vitro virulence}

Once the EhCP112 silencing was achieved, we determined its effect on the in vitro virulence of E. histolytica. First, the protease activity of the silenced trophozoites was analyzed in polyacrylamide- $0.1 \%$ gelatin substrate gels. The EhCP112-silenced trophozoites showed a 62$\mathrm{kDa}$ band with smaller proteinase activity to that of trophozoites treated with the non-related sequence (NRS) and untreated trophozoites (Figure 4A). Densitometry of that band revealed a 55\% minor activity in EhCP112silenced trophozoites with respect to controls, whereas the $49-\mathrm{kDa}$ band showed similar activity in all conditions (Figure 4A). The $62-\mathrm{kDa}$ band could correspond to the active EhCP112 enzyme; its higher molecular weight is probably due to the native electrophoretic conditions. Nevertheless, these assays suggested that EhCP112 silencing has a significant effect only in one band with protease activity in substrate gels.

In order to analyze the cytotoxic activity of total extracts from EhCP112-silenced trophozoites, total amoeba extracts were incubated with MDCK monolayers during $2 \mathrm{~h}$ and then the monolayer destruction was evaluated. Results showed that silenced trophozoites presented a significantly reduction in the cytotoxic activity (25\%) in relation to the NRS-treated trophozoites (Figure 4B), suggesting that EhCP112 has a relevant role in cytolysis.

In these assays we evaluated the monolayer cell destruction by total trophozoite extracts, where all the amoeba cysteine proteinases have been released. Nevertheless, there are few cysteine proteinases, including EhCP112, reported to be secreted that could be involved in cytolysis $[26,48]$. To analyze the role of EhCP112 in cell destruction by trophozoites, we performed cytopathic assays using EhCP112-silenced trophozoites on MDCK monolayers. These experiments showed a significant decrease of $25 \%$ in cell destruction by the EhCP112-silenced trophozoites in comparison with the cell destruction performed by the NRS-treated trophozoites (Figure 4C), eliciting the EhCP112 activity in cell destruction and tissue invasion.

We also carried out erytrophagocytosis assays, because phagocytosis is an event involved in the pathogenic mechanism of E. histolytica [28]. Thus, we evaluated the ingestion of human red blood cells (RBC) during 5 and 10 min by the EhCP112-silenced and NRS-treated trophozoites. For these assays, the phagocytic value obtained from NRS-treated trophozoites at 10 min of phagocytosis was arbitrary taken as $100 \%$ efficiency. At 5 min of incubation, the difference between the EhCP112-silenced and the NRS-treated trophozoites was 19\%; silenced trophozoites showed a phagocytosis efficiency of $44 \%$, whereas NRS-treated trophozoites displayed an efficiency of $63 \%$ (Figure 4D). At $10 \mathrm{~min}$ of incubation, the difference between these populations was $34 \%$; silenced trophozoites showed 66\% of phagocytosis efficiency (Figure 4D). These results suggest that EhCP112 could be involved in the phagocytic activity of E. histolytica.

Data obtained in this study support the hypothesis that EhCP112 is involved in the pathogenicity of E. histolytica. However, despite that expression of EhCP112 decreased around $89 \%$ after incubation with siRNA, cell cytotoxicity, cytopathic effect and erythrocyte phagocytosis between siRNA and NRS treated trophozoites showed minor, but significant, differences (25 to 34\%). These results suggest that other mechanisms might also contribute in these processes.

On the other hand, it has been reported that the expression of the homologue of EhCP112 in E. invadens, a related parasite of reptilians, is increased in the cyst stage [49], suggesting that this CP could also participate in development of the life cycle in Entamoeba sp. The EhCP112 silencing could be useful to test this possibility; unfortunately the in vitro encystation of $E$. histolytica is not still available.

\section{Conclusions}

In this study we achieved the silencing of EhCP112 by siRNA. The highest silencing effect was detected at $16 \mathrm{~h}$ of treatment; time enough to perform the in vitro virulence assays, which showed that EhCP112 silencing produces a significant reduction in cytolysis and phagocytosis, indicating the participation of EhCP112 in these events. These results and those obtained with the EhCP112 recombinant protein [26] support the use of EhCP112, in combination with other virulence factors of E. histolytica, as a therapeutic target or a vaccine candidate.

\section{Abbreviations \\ BLAST: Basic Local Alignment Search Tool; CPs: Cysteine proteinases; EhCP112: Cysteine proteinase of E. histolytica which is part of the EhCPADH protein complex; hRBCs: Human red blood cells; IPTG: Isopropyl B-D-1- thiogalactopyranoside; MDCK: Madin-Darby canine kidney cell line; NRS: Non-related sequence; PBS: Phosphate buffered saline; rEhCP112: EhCP112 recombinant protein; siRNA: Small interference RNA.}

Competing interests

The authors declare that they have no competing interests.

Authors' contributions

ROR and WF conceived and carried out experiments, analyzed data and drafted the manuscript; MBM, ROQ and EO participated in the design of the study, analyzed data and helped to draft the manuscript; MAR conceived and designed the study, analyzed data and drafted the manuscript. All authors read and approved the final manuscript. 


\section{Acknowledgements}

This work was supported by Consejo Nacional de Ciencia y Tecnología (CONACyT, Mexico). We thank Carlos Vazquez Calzada and Mario Rodriguez Nieves for their technical assistance.

\section{Author details}

${ }^{1}$ Departamento de Infectómica y Patogénesis Molecular, CINVESTAV-IPN, A.P. 14-740, México, D.F., México. ${ }^{2}$ Universidad Autónoma de la Ciudad de México, San Lorenzo No. 290. Colonia Del Valle. Delegación Benito Juárez. C. P 03100, México, D.F., México.

Received: 13 April 2013 Accepted: 24 August 2013

Published: 28 August 2013

\section{References}

1. Stanley SL Jr: Amoebiasis. Lancet 2003, 361(9362):1025-1034.

2. W.H.O: WHO Weekly Epidemiological Record. Geneve 1997, 72:97-100.

3. Ravdin Jl, Croft BY, Guerrant RL: Cytopathogenic mechanisms of Entamoeba histolytica. J Exp Med 1980, 152(2):377-390.

4. Faust DM, Guillen N: Virulence and virulence factors in Entamoeba histolytica, the agent of human amoebiasis. Microbes Infect 2012, 14(15):1428-1441.

5. McKerrow JH, Sun E, Rosenthal PJ, Bouvier J: The proteases and pathogenicity of parasitic protozoa. Annu Rev Microbiol 1993, 47:821-853.

6. Alderete JF, Provenzano D: The vagina has reducing environment sufficient for activation of Trichomonas vaginalis cysteine proteinases. Genitourin Med 1997, 73(4):291-296

7. Alvarez-Sanchez ME, Avila-Gonzalez L, Becerril-Garcia C, Fattel-Facenda LV, Ortega-Lopez J, Arroyo R: A novel cysteine proteinase (CP65) of Trichomonas vaginalis involved in cytotoxicity. Microb Pathog 2000, 28(4):193-202.

8. Mendoza-Lopez MR, Becerril-Garcia C, Fattel-Facenda LV, Avila-Gonzalez L, Ruiz-Tachiquin ME, Ortega-Lopez J, Arroyo R: CP30, a cysteine proteinase involved in Trichomonas vaginalis cytoadherence. Infect Immun 2000, 68(9):4907-4912

9. Klemba M, Goldberg DE: Biological roles of proteases in parasitic protozoa. Annu Rev Biochem 2002, 71:275-305.

10. Sajid M, McKerrow JH: Cysteine proteases of parasitic organisms. Mol Biochem Parasitol 2002, 120(1):1-21.

11. Rosenthal PJ, Ring CS, Chen X, Cohen FE: Characterization of a Plasmodium vivax cysteine proteinase gene identifies uniquely conserved amino acids that may mediate the substrate specificity of malarial hemoglobinases. J Mol Biol 1994, 241(2):312-316.

12. Bruchhaus I, Jacobs T, Leippe M, Tannich E: Entamoeba histolytica and Entamoeba dispar: differences in numbers and expression of cysteine proteinase genes. Mol Microbiol 1996, 22(2):255-263.

13. Bart G, Frame MJ, Carter R, Coombs GH, Mottram JC: Cathepsin B-like cysteine proteinase-deficient mutants of Leishmania mexicana. Mol Biochem Parasitol 1997, 88(1-2):53-61.

14. Omara-Opyene AL, Gedamu L: Molecular cloning, characterization and overexpression of two distinct cysteine protease cDNAs from Leishmania donovani chagasi. Mol Biochem Parasitol 1997, 90(1):247-267.

15. Tomas AM, Miles MA, Kelly JM: Overexpression of cruzipain, the major cysteine proteinase of Trypanosoma cruzi, is associated with enhanced metacyclogenesis. Eur J Biochem 1997, 244(2):596-603.

16. Hellberg A, Nowak N, Leippe M, Tannich E, Bruchhaus I: Recombinant expression and purification of an enzymatically active cysteine proteinase of the protozoan parasite Entamoeba histolytica. Protein Expr Purif 2002, 24(1):131-137.

17. Joshi PB, Kelly BL, Kamhawi S, Sacks DL, McMaster WR: Targeted gene deletion in Leishmania major identifies leishmanolysin (GP63) as a virulence factor. Mol Biochem Parasitol 2002, 120(1):33-40.

18. Que $X$, Brinen LS, Perkins P, Herdman S, Hirata K, Torian BE, Rubin H, McKerrow JH, Reed SL: Cysteine proteinases from distinct cellular compartments are recruited to phagocytic vesicles by Entamoeba histolytica. Mol Biochem Parasitol 2002, 119(1):23-32.

19. Mottram JC, Helms MJ, Coombs GH, Sajid M: Clan CD cysteine peptidases of parasitic protozoa. Trends Parasitol 2003, 19(4):182-187.

20. Skelly PJ, Da'dara A, Harn DA: Suppression of cathepsin B expression in Schistosoma mansoni by RNA interference. Int J Parasitol 2003, 33(4):363-369.
21. Kissoon-Singh V, Mortimer L, Chadee K: Entamoeba histolytica cathepsinlike enzymes : interactions with the host gut. Adv Exp Med Biol 2011, 712:62-83.

22. Bruchhaus I, Loftus BJ, Hall N, Tannich E: The intestinal protozoan parasite Entamoeba histolytica contains 20 cysteine protease genes, of which only a small subset is expressed during in vitro cultivation. Eukaryot Cell 2003, 2(3):501-509.

23. Tillack M, Biller L, Irmer H, Freitas M, Gomes MA, Tannich E, Bruchhaus I: The Entamoeba histolytica genome: primary structure and expression of proteolytic enzymes. BMC Genomics 2007, 8:170.

24. Garcia-Rivera G, Rodriguez MA, Ocadiz R, Martinez-Lopez MC, Arroyo R, Gonzalez-Robles A, Orozco E: Entamoeba histolytica : a novel cysteine protease and an adhesin form the $112 \mathrm{kDa}$ surface protein. Mol Microbiol 1999, 33(3):556-568.

25. Arroyo R, Orozco E: Localization and identification of an Entamoeba histolytica adhesin. Mol Biochem Parasitol 1987, 23(2):151-158.

26. Ocadiz R, Orozco E, Carrillo E, Quintas LI, Ortega-Lopez J, Garcia-Perez RM, Sanchez T, Castillo-Juarez BA, Garcia-Rivera G, Rodriguez MA: EhCP112 is an Entamoeba histolytica secreted cysteine protease that may be involved in the parasite-virulence. Cell Microbiol 2005, 7(2):221-232.

27. Quintas-Granados LI, Orozco E, Brieba LG, Arroyo R, Ortega-Lopez J: Purification, refolding and autoactivation of the recombinant cysteine proteinase EhCP112 from Entamoeba histolytica. Protein Expr Purif 2009, 63(1):26-32.

28. Orozco E, Guarneros G, Martinez-Palomo A, Sanchez T: Entamoeba histolytica. Phagocytosis as a virulence factor. J Exp Med 1983, 158(5):1511-1521.

29. Diamond LS, Harlow DR, Cunnick CC: A new medium for the axenic cultivation of Entamoeba histolytica and other Entamoeba. Trans R SoC Trop Med Hyg 1978, 72(4):431-432.

30. Sambrook J, Russell D: Molecular cloning. A laboratory manual. 3rd edition. New York: Cold Spring Harbor Laboratory Press; 2001

31. siRNA target finder (Ambion). http://www.ambion.com/techlib/misc/ siRNA finder.html.

32. Basic Alignment Research Tool. http://blast.ncbi.nlm.nih.gov/Blast.cgi.

33. multiple sequence alignment ClustalW. http://www.ebi.ac.uk/Tools/msa/ clustalw2/.

34. Entamoeba genome database Pathema. http://blast.jcvi.org/pathema-blast/ index.cgi?project=entamoeba.

35. Bracha R, Mirelman D: Virulence of Entamoeba histolytica trophozoites. Effects of bacteria, microaerobic conditions, and metronidazole. J Exp Med 1984, 160(2):353-368.

36. Voigt H, Olivo JC, Sansonetti P, Guillen N: Myosin IB from Entamoeba histolytica is involved in phagocytosis of human erythrocytes. J Cell SC 1999, 112(Pt 8):1191-1201.

37. Martinez-Lopez C, Orozco E, Sanchez T, Garcia-Perez RM, HernandezHernandez F, Rodriguez MA: The EhADH112 recombinant polypeptide inhibits cell destruction and liver abscess formation by Entamoeba histolytica trophozoites. Cell Microbiol 2004, 6(4):367-376.

38. Madriz X, Martinez MB, Rodriguez MA, Sierra G, Martinez-Lopez C, Riveron AM, Flores L, Orozco E: Expression in fibroblasts and in live animals of Entamoeba histolytica polypeptides EhCP112 and EhADH112. Microbiol 2004, 150(Pt 5):1251-1260.

39. Simpson JC, Joggerst B, Laketa V, Verissimo F, Cetin C, Erfle H, Bexiga MG, Singan VR, Heriche JK, Neumann B, et al: Genome-wide RNAi screening identifies human proteins with a regulatory function in the early secretory pathway. Nat Cell Biol 2012, 14(7):764-774.

40. Landmann F, Foster JM, Slatko BE, Sullivan W: Efficient in vitro RNA interference and immunofluorescence-based phenotype analysis in a human parasitic nematode, Brugia malayi. Parasit Vectors 2012, 5:16.

41. Alvarez-Calderon F, Gregory MA, Degregori J: Using functional genomics to overcome therapeutic resistance in hematological malignancies. Immunol Res 2013, 55((1-3)):100-115

42. Seth S, Johns R, Templin MV: Delivery and biodistribution of siRNA for cancer therapy: challenges and future prospects. Ther Deliv 2012, 3(2):245-261.

43. Vayssie L, Vargas M, Weber C, Guillen N: Double-stranded RNA mediates homology-dependent gene silencing of gamma-tubulin in the human parasite Entamoeba histolytica. Mol Biochem Parasitol 2004, 138(1):21-28.

44. Boettner DR, Huston CD, Linford AS, Buss SN, Houpt E, Sherman NE, Petri WA Jr: Entamoeba histolytica phagocytosis of human erythrocytes 
involves PATMK, a member of the transmembrane kinase family. PLoS Pathog 2008, 4(1):e8.

45. Linford AS, Moreno H, Good KR, Zhang H, Singh U, Petri WA Jr: Short hairpin RNA-mediated knockdown of protein expression in Entamoeba histolytica. BMC Microbiol 2009, 9:38.

46. Solis CF, Santi-Rocca J, Perdomo D, Weber C, Guillen N: Use of bacterially expressed dsRNA to downregulate Entamoeba histolytica gene expression. PLoS One 2009, 4(12):e8424.

47. Mancilla-Herrera I, Mendez-Tenorio A, Wong-Baeza I, Jimenez-Uribe AP, Alcantara-Hernandez M, Ocadiz-Ruiz R, Moreno-Eutimio MA, Arriaga-Pizano LA, Lopez-Macias C, Gonzalez-y-Merchand J, et al: A Toll/IL-1R/resistance domain-containing thioredoxin regulates phagocytosis in Entamoeba histolytica. Parasit Vectors 2012, 5:224.

48. Keene WE, Petitt MG, Allen S, McKerrow JH: The major neutral proteinase of Entamoeba histolytica. J Exp Med 1986, 163(3):536-549.

49. Ebert F, Bachmann A, Nakada-Tsukui K, Hennings I, Drescher B, Nozaki T, Tannich E, Bruchhaus I: An Entamoeba cysteine peptidase specifically expressed during encystation. Parasitol Int 2008, 57(4):521-524.

doi:10.1186/1756-3305-6-248

Cite this article as: Ocádiz-Ruiz et al:: Effect of the silencing of the

Ehcp112 gene on the in vitro virulence of Entamoeba histolytica. Parasites \& Vectors 2013 6:248.

\section{Submit your next manuscript to BioMed Central and take full advantage of:}

- Convenient online submission

- Thorough peer review

- No space constraints or color figure charges

- Immediate publication on acceptance

- Inclusion in PubMed, CAS, Scopus and Google Scholar

- Research which is freely available for redistribution 